continued for 18 months, but there was no benefit. In contrast, another trial ${ }^{12}$ using a tyrosine-adsorbed extract given for a year to children did find some benefit. All these patients had a reaction to a bronchial provocation test, and in many it was a dual reaction. In the ones who showed most improvement the late reaction was lost while the immediate reaction was unchanged-an observation which shows how little we understand of hyposensitisation.

On present evidence it does not seem worth giving $D$ pteronyssinus extract to adult asthmatics who have a positive skin test result and get worse on exposure to house dust. Fairly prolonged hyposensitisation may be beneficial, however, in young asthmatics in whom the relevance of the mite to the asthma has been more firmly established by a bronchial provocation test.

\footnotetext{
1 Davies RJ. Allergic lung disease. Br $\mathcal{F}$ Hosp Med 1979;22:136-50.

${ }^{2}$ Research Committee of the British Thoracic and Tuberculosis Association. Skin tests and clinical features of asthma. $\mathrm{Br} \mathcal{F}$ Dis Chest $1975 ; 69: 125-36$.

3 Taylor AJN, Davies RJ, Hendrick DJ, Pepys J. Recurrent nocturnal asthmatic reactions to bronchial provocation tests. Clin Allergy 1979;9: 213-9.

${ }^{4}$ Purcell K, Brady $\mathrm{K}$, Chai $\mathrm{H}$, et al. The effect on asthma in children of experimental separation from the family. Psychosom Med 1969;31: 144-64.

5 Sarsfield JK, Gowland G, Toy R, Norman ALE. Mite-sensitive asthma of childhood. Arch Dis Child 1974;49:716-21.

${ }^{6}$ Burr ML, St Leger AS, Neale E. Anti-mite measures in mite-sensitive adult asthma. A controlled trial. Lancet 1976;i:333-5.

7 Penaud A, Nourrit J, Timon-David P, et al. Results of a controlled trial of the acaricide paragerm on Dermatophagoides spp in dwelling houses. Clin Allergy 1977;7:49-53.

${ }^{8}$ Gaddie J, Skinner C, Palmer KNV. Hyposensitisation with house dust mite vaccine in bronchial asthma. $\mathrm{Br}$ Med F 1976;ii:561-3.

${ }^{9}$ Newton DAG, Maberley DJ, Wilson R. House dust mite hyposensitisation. $\mathrm{Br} \mathcal{F}$ Dis Chest 1978;72:21-8.

10 D'Souza MF, Pepys J, Wells ID. Hyposensitisation with Dermatophagoides pteronyssinus in house dust allergy: a controlled study of clinical and immunological effects. Clin Allergy 1973;3:177-93.

11 Mite Allergy Subcommittee of the Research Committee of the British Thoracic Association. A trial of house dust mite extract in bronchial asthma. $\mathrm{Br} \mathcal{F}$ Dis Chest 1979;73:260-70.

12 Warner JO, Price JF, Soothill JF, Hey EN. Controlled trial of hyposensitisation to Dermatophagoides pteronyssinus in children with asthma. Lancet 1978 ;ii:912-5.
}

\section{Second-best prostatectomy?}

One in every 10 men who pass the age of 40 will sooner or later need an operation for benign enlargement of the prostate. In England and Wales over $80 \%$ of these operations are performed by general surgeons using (as a rule) one of the open operations which require an abdominal incision and the enucleation of the adenoma from its "capsule." The technique has altered little since the turn of the century. Yet, unless the adenoma is exceptionally large, it may be removed equally completely piecemeal through the urethra using a resectoscope -an operation that is virtually painless, needs half the time in hospital, and has a low complication rate and a mortality less than half that of any of the open techniques. Nor are the results inferior: indeed, the success rate after transurethral surgery is in some respects better than after open operations. ${ }^{1}$ Why, then, is transurethral resection not employed universally?

Firstly, a handful of patients have enormous adenomas and the resectoscope cannot be manoeuvred past them with safety, but such people are rare. More usually transurethral resection is not performed because the surgeon has not been trained in the method. The technique is not easy either to learn or to teach, and if it is to be done safely it demands protracted apprenticeship and specialisation in urological surgery. Without this specialisation the resectoscope may cause havoc, and general surgeons without special training are wise to prefer open operations.

In 1975 the number of specialist urologists in England and Wales was examined by Ashley and Collingwood at the London School of Hygiene and Tropical Medicine. Many young surgeons would like to be trained in urology, but even now there are not jobs for those who have completed their accredited senior registrarships. What is holding progress back? As often, the problem is the shortage of money for salaries. At present a specialist urologist can usually be appointed only by replacing a general surgeon. In a small hospital this may mean that a weary general surgeon, used to being on call one night in three, has then to expect to be on call every other night, for the newly appointed specialist urologist will usually not be adequately trained to cope with a haematemesis or a vascular catastrophe. The general surgeon with an interest in urology does not exist.

Furthermore, many well-trained and dedicated general surgeons, who learnt all there was to learn of urology 20 years ago, are unconvinced of the need for specialist urologists and do not accept the superiority of transurethral over open prostatectomy. The figures, however, do not support their view. Ten years ago, when Ashley, Howlett, and Morris ${ }^{2}$ compared two teaching hospitals with three regional board hospitals, they found a discrepancy in mortality for prostatic hyperplasia of $1.6 \%$ versus $7.6 \%$. What they did not point out was the even worse disparity in mortality among the three hospitals with urological specialists $(2.0 \%)$ versus the two without $(11 \cdot 2 \%)$. Though there has been debate about the exact meaning of these figures, more recently Leach has reported from a district general hospital an overall mortality of $2.3 \%$ in 600 prostatectomies, mostly done by open methods: one death occurred in a man of only $54 .^{3}$ This mortality is double what would be expected of a contemporary urological service offering mainly transurethral resection. ${ }^{4}$

Things are better managed in Scotland, where urology has been accepted as a separate discipline for a generation. As long ago as 1969-74 the average mortality for prostatectomy was $2 \%$, and in the last of those years $68 \%$ of operations were being done transurethrally with a death rate of only $1.5 \% .^{5}$ Equally impressive was the difference in duration of hospital stay, which was three to four days less for transurethral than for open prostatectomy. Argyrou et $a l^{5}$ calculated that the money saved by this shorter hospital stay was more than enough to pay for the increase in establishment of specialist urologists needed.

The clinical argument should be that the need for urological skill is not confined to the prostate: its advantages are even more definite for patients with cancer of the bladder or urinary calculi, but the numbers are less easy to extract and compare. Alas, for the humble prostate the difference in results between the specialist and the generalist are there for all to see.

${ }^{1}$ Chilton CP, Morgan RJ, England HR, Paris AM, Blandy JP. A critical evaluation of the results of transurethral resection of the prostate. Br f Urol 1978;50:542-6.

2 Ashley JSA, Howlett A, Morris JN. Case-fatality of hyperplasia of the prostate in two teaching and three regional-board hospitals. Lancet 1971 ;ii:1308-11.

${ }^{3}$ Leach RD. Prostatectomy at a district general hospital. Ann R Coll Surg Engl 1979;61:459-62.

* Graham AG. Scottish prostates: a 6-year review. Brf Urol 1977;49:679-82.

5 Argyrou S, Blandy JP, Gow JG, Singh M, Tresidder GC, Vinnicombe J. Price of prostatectomy. Br Med F;1974:511-3. 